\title{
Clinical observations on sensory effects of trigeminal dorsal root section'
}

\author{
ADOLFO LEY AND JOSÉ Ma. GUITART \\ From the Neurosurgical Clinic, University of Barcelona Medical School, Barcelona, Spain
}

SUMMARY Further clinical and operative support is presented for Dandy's discovery in 1929 o $\frac{\overline{\frac{5}{6}}}{4}$ the presence of accessory sensory fibres of the fifth cranial nerve, running a separate course from the main sensory root at its exit from the pons. The advantages are stressed of Dandy's subcerebella? approach in selected cases for sparing those fibres as well as the motor root.

It is well known that Dandy in 1925 advocated trigeminal dorsal root division by what he called the subcerebellar route, for the relief of major trigeminal neuralgia. Four years later he published his first series of 88 cases operated on through this approach (Dandy, 1929). He was so surprised by the great variability in both the quantity and quality of the retained sensation, that, in his own words, '. . . one's credulity might well be tested'. Later on, when it became evident to him that by partial section of the root the pain was cured and, at the same time, the sensation to the entire domain of the fifth nerve little disturbed, he deliberately left intact from one third to one fourth of the root.

Dandy's suboccipital approach does not seem to have appealed much to neurosurgeons, probably because it seems to involve greater risks for the elderly group of patients suffering from major trigeminal neuralgia.

In the few published series of cases oparated by the subtentorial approach such as those of van Wagenen (1931), Hyndman (1938), Guidetti (1950) (this series was from Olivecrona's clinic), Walker, Miles, and Simpson (1956), and Johnson (1963) the trigeminal root was only partially sectioned, and it seems as if most authors have ignored the striking preservation of sensation found by Dandy in his first 23 cases, some attributing it to incompleteness of the root section (Davis and Haven, 1933; Stookey and Ransohoff, 1959).

For many years we used almost exclusively Frazier's subtemporal approach for the surgical treatment of major trigeminal neuralgia. The area of

1Presented in a TV Panel at the IVth International Congress of Neurological Surgery, New York, N.Y., September 1969. anaesthesia we found in most cases after totab section of the sensory root corresponded with the pattern described by Cushing (1904) and Davieso (1907). Whenever sensation to light touch, pinprick ${ }_{p}^{\omega}$ or mild temperature was preserved in that area, attributed it to partial or incomplete section of sensory root.

Later on, moved mainly by the desire to investi응 gate the aetiopathogenesis of trigeminal neuralg we operated on by the suboccipital approach a smoll carefully selected group of patients suffering from major trigeminal neuralgia, which was bilateral two cases. One of the latter patients died from pogtoperative haemorrhage (in this case dorsal root section was done on one side and Sjöqvist's tractoo tomy on the other). In half of the 29 patients whos survived the operation the resulting anaesthesia was markedly reduced, the most striking case being tha of a 46 year old man in whom the neuralgia was produced by a fusiform enlargement of the basila $\overrightarrow{\overrightarrow{0}}$ artery. At operation the sensory root was carefully 3 freed from the enlarged artery and completely severed. The most remarkable finding after the operation was that the loss of sensation in the territory of the left fifth nerve was so mild that the patient could notice it only by fine comparison with? the normal side.

There were two more cases in which the initiab sensory loss which also extended to the territory of the three divisions later diminished to such ang extent as to become scarcely detectable.

As can be seen in Table 1, the sensory change found in our 29 cases were distributed as follows In 14 cases $(48.3 \%)$ there was complete anaesthesiæ to touch, pain, and temperature in the territory of the three main divisions of the fifth nerve. In 12 cases $(41 \%)$ the sensory loss, which involved the three 
T ABLE 1

SENSORY LOSS RESULTING FROM APPARENTLY TOTAL SECTION OF TRIGEMINAL DORSAL ROOT NEAR PONS

\begin{tabular}{lrr}
\hline \multicolumn{1}{c}{ Type and distribution of anaesthesia } & \multicolumn{2}{c}{ Cases } \\
& (no.) & (\%) \\
\hline Total in the three divisions & 14 & $48 \cdot 3$ \\
Partial in the three divisions & 12 & $41 \cdot 4$ \\
Frastional (in only one or two divisions) & 3 & $10 \cdot 3$ \\
\hline & 29 & $100 \cdot 0$ \\
\hline
\end{tabular}

divisions, was only partial, the three cases with minimal hypoaesthesia we have already mentioned being among them. In the remaining three cases, the sensory loss was limited to the territory of the second and third divisions. In none of the cases of the last two groups could a complete anaesthesia to light touch be detected anywhere in the territory of the fifth nerve, and only three had complete analgesia, one in the whole trigeminal area and the other two in the territory of the third division.

Our findings are in accordance with those published by Dandy (1929), though the figures and distribution of sensory changes do not exactly correspond. In his series of 23 cases in which a complete section of the sensory root by the subcerebellar route was done, only four $(17 \cdot 3 \%)$ had complete anaesthesia in the three divisions; 17 had incomplete anaesthesia over the three divisions, and, in two, the sensory loss was fragmentary-that is, limited to the territory of two divisions-but, contrary to our findings, the two divisions that were spared were the 2 nd and 3 rd.

Pertuiset (1963) has lately reported a complete section of the trigeminal root near the pons in 30 cases. Though he uses a transtentorial approach, his results as to sensory loss have been similar to those of Dandy and ourselves.

These remarkable findings made us think that the sparing of sensation that we occasionally had found after apparently total dorsal root section by the subtemporal approach could be due to the same cause, and not merely to the incompleteness of the section as we formerly believed. In order to assess that, we went over the records of 334 cases of major trigeminal neuralgia that we had operated on by the subtemporal approach, and selected 161 cases in which the operative reports made it presumable that a complete section had been done. The group includes also a number of cases in which, though the surgeon thought that only a partial section had been performed, the resulting anaesthesia was found to be complete over the entire trigeminal area. This study showed that only in 115 cases $(71.4 \%)$ was the resulting anaesthesia complete.

We are fully aware of the fallacy inherent in any statistical analysis based on sensory finding where psychological factors play such an important role both from the patient and the observer side. Besides, in considering our series, one has to take into account that apart from the senior author no less than seven other surgeons-most of them at the end of their training period-had done some of the operations, and that the examinations, carried out also by different observers, were often incomplete.

Even with all these limitations in mind, we have the impression that the fact that only $71.4 \%$ of the cases had complete anaesthesia is of some significance. Nevertheless, the most outstanding fact was the difference in the results obtained operating by the two ways, as can be seen in Table 2 .

In this Table, we have added the results obtained by us with subtentorial neurotomy to those of Dandy, plotting them against those of the 161 cases in which we assumed that a total neurotomy has been done by the subtemporal approach. The statistical analysis applying to the whole problem Pearson's $\chi^{2}$ test, showed that the probabilities for the differences in results between the two series being merely due to chance was less than 1 in 1,000 , which, in statistical terms, means 'very significant'.

At this point, therefore, we were confronted with two problems: one was why sensation could be preserved after presumed total trigeminal sensory root division; the other, why the preservation of sensation was more frequent when the neurotomy is done near the pons.

It is well known that, since the beginning of fifth nerve surgery at the end of the last century, outstanding surgeons such as Hartley (1893), Rose (1894, 1902), Krause (1896), Sapezko (1901), Kidd (1909), Maloney and Kennedy (1911), Souques (1924), Hartmann (1924), and others, had reported either the preservation or early restoration of sensation in the face after ablation of the Gasserian ganglion; the case reported by Fehleisen and Westerfeld in 1901 being of particular interest because the

TA B LE 2

COMPARATIVE SENSORY LOSS RESULTING FROM APPARENTLY TOTAL SECTION OF TRIGEMINAL DORSAL ROOT

\begin{tabular}{lrrrr}
\hline Type and distribution of anaesthesia & \multicolumn{4}{c}{ Type of operation } \\
\cline { 2 - 5 } & \multicolumn{2}{c}{ Dandy } & \multicolumn{2}{c}{ Frazier } \\
\cline { 2 - 5 } & Cases & $\%$ & Cases & $\%$ \\
\hline Total in the three divisions & 18 & 34.6 & 115 & $71 \cdot 4$ \\
Partial in the three divisions & 29 & $55 \cdot 7$ & 32 & $19 \cdot 8$ \\
Fractional (in only one or two divisions) & 5 & 9.6 & 14 & $8 \cdot 7$ \\
\hline & 52 & & 161 & \\
\hline
\end{tabular}


interruption of the fifth nerve was later verified at necropsy.

Various hypotheses have been advanced in order to explain those abnormal findings. The most widely accepted is based on a supplementary afferent innervation carried by the 7th cranial nerve and nervus intermedius (Hunt, 1937; White and Sweet, 1955; Sachs, 1968). However, going back to our clinical observations, it may be worth while to point out the apparently paradoxical fact that in five of the 15 cases in our series, operated on by the subtentorial approach in which sensation was more or less preserved, some impairment of function of the 7 th nerve was noticed, while in the other 14 in which anaesthesia was complete, the facial nerve was not affected. Something similar happened with the cases operated by the subtemporal approach, the proportion of facial nerve impairment among those with spared sensation being four times greater than in those in which the anaesthesia was complete.

The role played by the 9th and 10th nerves, as well as the upper cervical roots in providing supplementary innervation for the somatic area innervated by the trigeminal nerve, seems to be more restricted. Nevertheless, we have to admit that, both centrally and at the periphery, the anatomical connections between the trigeminal system and the 7th, 9th, and 10th cranial nerves as well as the upper cervical roots, are very numerous. Functionally also, the existence of these connections seems to be proved by the interesting findings of Crue, Shelden, Pudenz, and Freshwater (1956), in their studies about trigger mechanisms in trigeminal neuralgia. It may be also significant that sensation in the face was never retained to such an extent in those cases in which we did combined rhizotomy of the trigeminal, glossopharyngeal, and upper cervical nerves for the relief of pain produced by malignancies of the face and neck.

An alternative pathway for supplementary conduction of somatic sensation after sensory root section could be the motor root which contains the afferent fibres from which originates the mesencephalic root and nucleus of the fifth nerve. However as Dandy (1929) pointed out, the motor root blends with the third division at some distance from its exit from the ganglion, thus making it difficult to explain how it could carry sensation from the territory of the first two divisions, which on the other hand are the two in which sensation is usually better preserved.

Even if any or all of these alternatives for supplementary somatosensory innervation of the territory of the fifth nerve are accepted, the question remains how to explain the greater preservation of sensation offered by the dorsal root section near the pons.

Searching for another explanation, Dandy (1929) found that the sensory root of the trigeminal nerve had a variable number of accessory aberrant branches running a separate course adjacent to the motores rootlets, on which the preservation of sensation could depend.

Unfortunately, though Dandy's drawings of these branches were very illustrative (Dandy, 1929), the description he gave as to their course was not verys precise, and therefore their existence was stilp questionable when we first reported our findings ato the Oslo meeting of the Scandinavian Society of Neurological Surgeons in September 1964.

Since then, Jannetta and Rand (1966) and Rando and Hoshek (1967), using the microneurosurgicals technique and transtentorial approach, have been ${ }^{\circ}$ able to identify clearly the intermediate fibres which $\overrightarrow{\vec{\omega}}$ are related to light touch sensation, preserving themo during selective rhizotomy for major trigeminal neuralgia. The photograph in the Figure beautifully? shows the accessory aberrant fibres of Dandy, called $w$ by Rand the portius intermedius of the sensory roof. $\omega$

Though our experience with microneurosurgery still too limited to enable us to endorse Rands? findings, we feel gratified to know that at last an anatomical explanation has been found for the striking differences in sensory loss produced by section of the dorsal root of the trigeminal nerve different levels.

Finally, we would like to point out that, for tho neurosurgeons who are not yet fully acquainted with the modern microneurosurgical techniques, the old posterior approach of Dandy still affords an easy way of preserving the motor root as well as the intermediate fibres related to light touch sensation $\frac{O}{\Phi}$ over the face and cornea in middle-aged patients $\stackrel{\varrho}{\Rightarrow}$ afflicted by major trigeminal neuralgia. It also has $\overrightarrow{\overrightarrow{0}}$ the advantage of allowing the preservation of the 5th nerve whenever the cause of the neuralgia is found and can be removed, as has happened to us on several occasions, mainly with intracranial epidermoid tumours.

\section{Addendum}

Since this paper was presented in a TV panel at the IVth International Congress of Neurological Surgery in New $\frac{7}{0}$ York, the authors have been able to confirm the existence of the intermediate or aberrant sensory fibres using the $N$ operative microscope through Dandy's posterior approach. Photographic illustrations of their findings will $N$ be presented at the IVth European Congress of Neuro- N logical Surgery. 


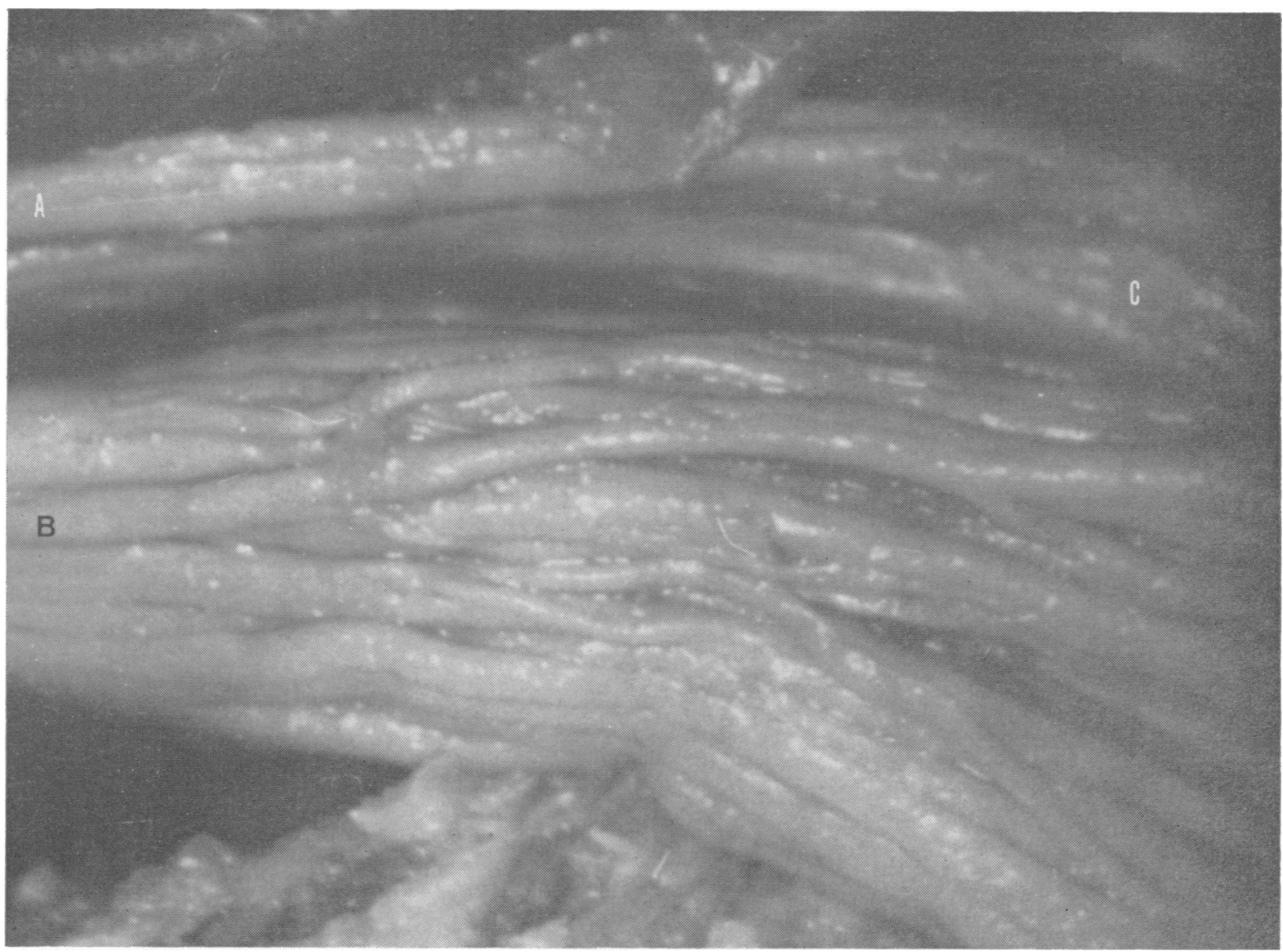

FIGURE Microphotograph of the motor (A) and sensory (B) roots of the trigeminal nerve, taken through the surgical microscope. Note the bundle of accessory or intermediate fibres $(\mathrm{C})$ crossing from the motor to the sensory roots. (Photograph by courtesy of Dr. R. W. Rand, of Los Angeles, California.)

\section{REFERENCES}

Crue, B. L., Shelden, C. H., Pudenz, R. H., and Freshwater, D. B. (1956). Observations on the pain and trigger mechanism in trigeminal neuralgia. Neurology (Minneap.), 6, 196-207.

Cushing, H. (1904). The sensory distribution of the fifth cranial nerve. Bull. Johns Hopkins Hosp., 15, 213-232.

Dandy, W. E. (1925). Section of the sensory root of the trigeminal nerve at the pons. Bull. Johns Hopkins Hosp., 36, 105-106.

Dandy, W. E. (1929). An operation for the cure of tic douloureux. Partial section of the sensory root at the pons. Arch. Surg., 18, 687-734.

Davies, H. M. (1907). The functions of the trigeminal nerve. Brain, 30, 219-276.

Davis, L., and Haven, H. A. (1933). Surgical anatomy of the sensory root of the trigeminal nerve. Arch. Neurol. Psychiat. (Chic.), 29, 1-18.

Fehleisen, F., and Westerfeld, O. F. (1901). The surgical department of the Germain Hospital 1898, September bis 1899, December. Centrbl. Chir., 28, 851-852.

Guidetti, B. (1950). Nevralgia essenziale del trigemino. Trattamento chirurgico: sezione subtotale delle fibre sensitive secondo Dandy. G. ital. Chir., 6, 13-21.
Hartley, F. (1893). Intracranial neurectomy of the fifth nerve. Ann. Surg., 17, 511-526.

Hartmann, E. (1924). La neurotomie rétro-gassérienne. Ses conséquences physiologiques et pathologiques. Contribution a l'étude de la kératite neuroparalytique. Thèse de Paris. no. 134.

Hunt, J. R. (1937). Geniculate neuralgia (neuralgia of the nervus facialis). A further contribution to the sensory system of the facial nerve and its neuralgic conditions. Arch. Neurol. Psychiat. (Chic.), 37, 253-285.

Hutchinson, J. (1905). The Surgical Treatment of Facial Neuralgia. John Bale, Sons \& Danielsson: London.

Hyndman, O. R. (1938). Tic douloureux. Partial section of the root of the fifth cranial nerve; a comparison of the subtemporal and cerebellar approaches from surgical and physiologic standpoints. Arch. Surg., 37, 74-99.

Jannetta, P. J., and Rand, R. W. (1966). Transtentorial retrogasserian rhizotomy in trigeminal neuralgia by microneurosurgical technique. Bull. Los Angeles neurol. Soc., 31, 93-99.

Johnson, A. C. (1963). The surgical treatment of trigeminal neuralgia with particular reference to juxtapontine partial division of the trigeminal sensory root. J. internat. Coll. Surg., 39, 171-176. 
Kidd, L. J. (1909). Lachrymal reflexes: Pressure sensibility of head and neck. Rev. neurol., 7, 167-180.

Krause, F. (1896). Die Neuralgie des Trigeminus, pp. 260. Vogel: Leipzig.

Maloney, W. J., and Kennedy, R. F. (1911). The sense of pressure in the face, eye, and tongue. Brain, 34, 1-28.

Pertuiset, B. (1963). Névralgie du trijumean section rétrogassérienne de la racine sensitive dans la fosse postérieure par voie temporale extra-durale (d'après 31 cas). Presse Méd., 71, 449-450.

Rand, R. W., and Hoshek, S. (1967). Microsurgical Neuroanatomy Atlas. H. L. Pierce: Los Angeles.

Rose, W. (1894). Notes of two cases of the Braun-Lossen operation for trigeminal neuralgia. Lancet, 1, 666-668.

Rose, W. (1902). A case of removal of the gasserian ganglion by Doyen's method (modified). Practitioner, 68, 552-559.

Sachs, E. Jr. (1968). The role of the nervus intermedius in facial neuralgia. Report of four cases with observations on the pathways for taste, lacrimation, and pain in the face. J. Neurosurg., 28, 54-60.

Sapeszko, K. (1901). Über Exstirpation des Ganglion Gasseri. Centrbl. Chir., 28, 430.

Souques, A., and Hartmann, E. (1924). Les fibres de la sensibilité profonde de la face passent-elles par le nerfe facial? Rev. neurol., 31, 86-87

Stookey, B., and Ransohoff, J. (1959). Trigeminal Neuralgia, pp. 366. Thomas: Springfield, Ill.

Van Wagenen, W. P. (1931). Some indications for section of the posterior root of the trigeminal nerve through posterior fossa. Ann. Surg., 94, 1013-1017.

Walker, E., Miles, F. C., and Simpson, J. R. (1956). Partial $\overrightarrow{\bar{F}}$ trigeminal rhizotomy using suboccipital approach. Arch. Neurol. Psychiat. (Chic.), 75, 514-521.

White, J. C., and Sweet, W. H. (1955). Pain: Its Mechanisws and Neurosurgical Control, pp. 736. Thomas: Springfield, Ill. 